\title{
Reversal of type 2 diabetes in youth who adhere to a very-low-energy diet: a pilot study
}

\author{
Megan L. Gow ${ }^{1,2}$ - Louise A. Baur ${ }^{1,3}$ • Nathan A. Johnson ${ }^{4}$ Chris T. Cowell ${ }^{2,5}$. \\ Sarah P. Garnett ${ }^{1,2,5}$
}

Received: 19 August 2016/Accepted: 4 November 2016 / Published online: 26 November 2016

(C) Springer-Verlag Berlin Heidelberg 2016

\begin{abstract}
Aims/hypothesis The aim of the study was to investigate whether a very-low-energy diet (VLED) is a feasible and acceptable treatment option for type 2 diabetes in children and adolescents, and whether adherence can lead to rapid weight loss, reversal of type 2 diabetes and reduced liver fat as seen in adult studies.

Methods Eight participants with type 2 diabetes and obesity, aged 7-16 years, non-medicated $(n=1)$ or treated with metformin $(n=7)$ and in some cases insulin $(n=3)$, followed a VLED ( $<3360 \mathrm{~kJ} /$ day) for 8 weeks, then transitioned to a hypocaloric diet $(\sim 6300 \mathrm{~kJ} /$ day $)$ that they followed to 34 weeks. $\mathrm{HbA}_{1 \mathrm{c}}$, fasting glucose and $2 \mathrm{~h}$ post-glucose load plasma glucose $(2 \mathrm{hG})$ were determined from fasting blood and an OGTT. Liver fat concentration was quantified using proton magnetic resonance spectroscopy. Adherence was defined as $\geq 5 \%$ weight loss during the 8 week VLED.

Results Adherers $(n=5)$ and non-adherers $(n=3)$ had median weight loss of $7.5 \%$ and $0.5 \%$, respectively, at 8 weeks.
\end{abstract}

Megan L. Gow

megan.gow@health.nsw.gov.au

1 Discipline of Child and Adolescent Health, University of Sydney, Sydney, NSW, Australia

2 Institute of Endocrinology and Diabetes, The Children's Hospital at Westmead, Corner of Hawkesbury Road and Hainsworth Street, Locked Bag 4001, Westmead, NSW 2145, Australia

3 The Children's Hospital at Westmead Clinical School, The Children's Hospital at Westmead, Sydney, NSW, Australia

4 Faculty of Health Sciences, University of Sydney, Sydney, NSW, Australia

5 Kids' Research Institute, The Children's Hospital at Westmead, Sydney, NSW, Australia
Overall, $\mathrm{HbA}_{1 \mathrm{c}}$ (mean [SE] 8.1\% [0.7\%] to 6.6\% [0.5\%]; $p=0.004)$ and $2 \mathrm{hG}(15.6[1.6] \mathrm{mmol} / \mathrm{l}$ to $11.3[1.0] \mathrm{mmol} / \mathrm{l}$; $p=0.009)$ were significantly reduced at 8 weeks compared with baseline. Liver fat was also significantly reduced from baseline $(14.7 \%[2.2 \%])$ to 8 weeks $(5.8 \%[1.7 \%] ; p=0.001)$. Only three out of eight participants met non-alcoholic fatty liver disease (NAFLD) criteria ( $\geq 5.5 \%$ ) at 8 weeks, compared with eight out of eight at baseline. The three participants on insulin therapy at baseline were able to cease therapy during the 8 week VLED. At 34 weeks, adherers $(n=5)$ achieved $12.3 \%$ weight loss, none met NAFLD criteria and four did not meet American Diabetes Association criteria for type 2 diabetes.

Conclusions/interpretation A VLED appears to be a feasible treatment option for some youth with type 2 diabetes on metformin therapy. Youth who agree to participate and adhere to a VLED achieve rapid weight loss, dramatic reductions in liver fat and reversal of type 2 diabetes. This highlights the capacity of a VLED to be used as a first-line treatment option in newly diagnosed youth. A larger trial with a control group and longer follow-up will be required to encourage a change in standard treatment.

Trial registration: Australian New Zealand Clinical Trial Registration Number (ACTRN) ACTRN12616000375459 (www.ANZCTR.org.au/ACTRN12616000375459.aspx).

Keywords Adolescents · Children · Liver fat · Type 2 diabetes $\cdot$ Very-low-energy diet $\cdot$ Youth

Abbreviations
$\begin{array}{ll}\text { 2hG } & 2 \mathrm{~h} \text { post-glucose load plasma glucose } \\ \text { ALT } & \text { Alanine transaminase } \\ \text { FPG } & \text { Fasting plasma glucose } \\ \text { GGT } & \gamma \text {-glutamyl transpeptidase } \\ \text { HRQOL } & \text { Health-related quality of life }\end{array}$




$\begin{array}{ll}{ }^{1} \text { H-MRS } & \text { Proton magnetic resonance spectroscopy } \\ \text { NAFLD } & \text { Non-alcoholic fatty liver disease } \\ \text { PedsQL } & \text { Pediatric Quality of Life Inventory } \\ \text { SHAKE IT } & \begin{array}{l}\text { Shakes and Meal Replacements to Help } \\ \text { Adolescents Kick-Start Healthy Eating in }\end{array} \\ & \begin{array}{l}\text { Type 2 Diabetes } \\ \text { Treatment Options for Type 2 Diabetes in } \\ \text { Adolescents and Youth }\end{array} \\ \text { TODAY } & \text { Urine albumin-to-creatinine ratio } \\ \text { UACR } & \text { Very-low-energy diet } \\ \text { VLED } & \text { Whole-body insulin sensitivity index } \\ \text { WBISI } & \end{array}$

\section{Introduction}

The prevalence of type 2 diabetes in young people is increasing in some populations $[1,2]$, and the aggressive clinical course is evident $[3,4]$. Current treatment guidelines aim to optimise glycaemic control and prevent complications through lifestyle intervention with metformin therapy $[5,6]$. However, findings from the Treatment Options for Type 2 Diabetes in Adolescents and Youth (TODAY) study (ClinicalTrials.gov identifier: NCT00081328) suggest this treatment may be ineffective in nearly $50 \%$ of youth [7]. Early and more intensive therapy has been proposed [8].

Both bariatric surgery and diet alone have effectively reversed type 2 diabetes in adults [9]. Several adult studies achieve reversal in as little as 7 days using a very-low-energy diet (VLED) [10-13], with no further requirement for medication. Prospective investigation of the capacity of a VLED to reverse type 2 diabetes in youth has not yet been examined.

The primary aims of this study were: (1) to determine the acceptability of the VLED; and (2) to determine whether completion of a VLED intervention and follow-up was associated with reversal of type 2 diabetes, improved glycaemic status, weight loss and reduced liver fat in youth. Secondary aims included describing changes in pancreatic fat, cardiometabolic risk factors, quality of life and eating behaviours following completion of the VLED intervention and follow-up period.

\section{Methods}

\section{Study design}

This pilot study, known as Shakes and Meal Replacements to Help Adolescents Kick-Start Healthy Eating in Type 2 Diabetes (SHAKE IT), was conducted at The Children's Hospital at Westmead, Sydney, NSW, Australia, and approved by the Sydney Children's Hospital Network Human Research Ethics Committee (12/SCHN/297). Written informed consent and assent from parents and the young person, respectively, were sought prior to enrolment. Participants were recruited between
June 2013 and March 2015 and completed the trial between March 2014 and December 2015. The study consisted of three phases: (1) phase I (0-8 weeks), VLED; (2) phase II (912 weeks), transition; (3) phase III (13-34 weeks), follow-up.

Assessments were undertaken at baseline and at 8 and 34 weeks. The primary outcome was the presence or absence of type 2 diabetes according to ADA criteria, i.e. $\mathrm{HbA}_{1 \mathrm{c}} \geq 6.5 \%$ ( $\geq 48 \mathrm{mmol} / \mathrm{mol}$ ), fasting plasma glucose $(\mathrm{FPG}) \geq 7.0 \mathrm{mmol} / \mathrm{l}$ or $2 \mathrm{~h}$ post-glucose load plasma glucose $(2 \mathrm{hG}) \geq 11.1 \mathrm{mmol} / \mathrm{l} \mathrm{be}$ ing indicative of type 2 diabetes [14].

\section{Participants}

Youth with a diagnosis of type 2 diabetes were recruited through paediatric endocrinologist referral and assessed for eligibility. Eligible youth were obese [15] and aged $<18$ years. Exclusion criteria included type 1 diabetes, secondary causes of obesity, psychiatric disturbance, on medication causing weight loss or gain (excluding insulin), and no English spoken by either parent/carer.

\section{Interventions}

Phase I (0-8 weeks): VLED The diet was a nutritionally complete (for youth) VLED (Optifast VLCD; Nestlé Australia, Sydney, NSW, Australia). Participants consumed four meal replacements (shake, soup, bar or dessert) daily, or three meal replacements and one meal (100-150 g lean, cooked meat and carbohydrate-free vegetables).

The diet was approximately $3360 \mathrm{~kJ} /$ day $(800 \mathrm{kcal} / \mathrm{day},<40 \%$ carbohydrate [ $\sim 50 \mathrm{~g} / \mathrm{day}], 40-55 \%$ protein and $<20 \%$ fat). Additional 'energy-free' foods could be consumed ad libitum to enhance compliance. Consumption of $\geq 21 /$ day of water or other energy-free beverages was encouraged. Participants were reviewed weekly by the study dietitian, with additional support given via regular telephone/text message contact.

Phase II (9-12 weeks): transition Participants were transitioned by week 12 to a reduced-energy diet, dropping one meal replacement at a time. Participants could remain on up to one daily meal replacement post transition. Weekly dietitian review was continued, with additional support given via regular telephone/text message contact.

Phase III (13-34 weeks): follow-up Participants continued their reduced-energy diet, aiming for further weight loss (5040-6300 kJ/day; 45-55\% moderate glycaemic index and minimal refined carbohydrate, $15-25 \%$ protein and $~ 30 \%$ fat $[\leq 10 \%$ saturated]). Dietitian review occurred every $2-4$ weeks, with additional support given via regular telephone/text message contact. 
Exercise No structured exercise intervention was included. However, regular physical activity was encouraged, consistent with guidelines for type 2 diabetes management in youth [6]. Participants were given an interactive pedometer (Fitbit One; Fitbit, San Francisco, CA, USA) to encourage activity, allowing monitoring and appropriate support from the study dietitian.

Metformin therapy was continued throughout the study as prescribed by the treating endocrinologist. Those on insulin therapy at baseline were monitored during the VLED phase to alter insulin dosage according to changes in glycaemic control. There were no hypoglycaemic events during the study.

\section{Assessments}

Medical Participants continued their regular diabetes clinic visits (3 monthly) with their endocrinologist. A diabetes educator reviewed each participant at commencement of the trial and throughout as clinically indicated. Demographics and family medical history were collected at baseline by questionnaire. A paediatric endocrinologist undertook a clinical review at baseline and at 8 and 34 weeks, including pubertal staging [16] at baseline.

Anthropometry, biochemistry and BP Weight, height and waist circumference were measured using standard procedures at baseline and at 8 and 34 weeks. Waist-to-height ratio and BMI $z$ scores were calculated [17], and obesity was defined according to International Obesity Task Force criteria [15].

After an overnight fast, a cannula was inserted for blood sampling. Fasting blood was drawn to determine $\mathrm{HbA}_{1 \mathrm{c}}$, glucose, insulin, lipids and liver enzymes. Dyslipidaemia was defined as abnormal levels of HDL cholesterol $(<1.03 \mathrm{mmol} / \mathrm{l})$ and/ or triacylglycerol ( $\geq 1.7 \mathrm{mmol} / \mathrm{l})$ [18]; abnormal liver enzymes were defined as alanine transaminase (ALT) and/or $\gamma$-glutamyl transpeptidase (GGT) $\geq 30 \mathrm{U} / 1$ [19, 20]. A $2 \mathrm{~h}$ OGTT was performed using a glucose dose of $1.75 \mathrm{~g} / \mathrm{kg}$ body weight to a maximum of $75 \mathrm{~g}$ to determine $2 \mathrm{hG}$ and insulin sensitivity. Whole-body insulin sensitivity index (WBISI) was calculated from the OGTT using the Matsuda index [21].

Spot urine samples were analysed for urine albumin-tocreatinine ratio (UACR). Microalbuminuria was defined as UACR $2.5-25.0 \mathrm{mg} / \mathrm{mmol}$ for boys and $3.5-25.0 \mathrm{mg} / \mathrm{mmol}$ for girls [22].

BP was measured using an automated BP monitor (Dinamap 1846SX; GE Healthcare, Chicago, IL, USA), and $z$ scores and percentiles were calculated from age-, sex- and height-specific reference values. Elevated BP was defined as systolic and/or diastolic $\mathrm{BP} \geq 90$ th percentile for age, sex and height [23].

Liver and pancreatic fat Liver and pancreatic fat concentration was measured by proton magnetic resonance spectroscopy $\left({ }^{1} \mathrm{H}-\mathrm{MRS}\right)$ using a $1.5 \mathrm{~T}$ Ingenia MRI system (Philips Medical Systems, Best, the Netherlands).
Image-guided, localised ${ }^{1} \mathrm{H}-\mathrm{MRS}$ spectra were acquired using single voxel $(3.0 \mathrm{~cm} \times 2.0 \mathrm{~cm} \times 2.0 \mathrm{~cm}$ for liver and $2.0 \mathrm{~cm} \times 1.0 \mathrm{~cm} \times 1.0 \mathrm{~cm}$ for pancreas) point resolved spectroscopy via the anterior and posterior arrays and Q-body transmit coil (repetition time $5000 \mathrm{~ms}$, echo time $45 \mathrm{~ms}, 512$ sample points), with 32 measurements acquired for the liver and 40 measurements for the pancreas. The volumes of interest were centred within the right lobe of the liver and the head of the pancreas. Subjects lay supine, with spectra acquired during quiet respiration.

Similar voxel placement was achieved between measures within individual, guided by image capture at baseline [24]. Fully automated high-order shimming was performed to ensure maximum field homogeneity.

Spectral data were post-processed by magnetic resonance user interface software (jMRUI, version 4.0; www.jmrui.eu $[25,26])$ by an assessor (NAJ) who was blinded to participant details and time point. Liver and pancreas water signal amplitudes were quantified using Hankel-Lanczos squares singular values decomposition [27-29], and a five resonance model was employed to fit the lipid peaks [24, 27, 30]. A liver fat concentration $\geq 5.5 \%$ was considered consistent with the presence of non-alcoholic fatty liver disease (NAFLD), as described by previous studies quantifying liver fat using ${ }^{1} \mathrm{H}$-MRS $[31,32]$.

Quality of life and eating behaviours Health-related quality of life (HRQOL) and psychological dimensions of eating behaviours were self-reported using the validated Pediatric Quality of Life Inventory (PedsQL) 4.0 Generic Core Scales [33] and Dutch Eating Behaviour Questionnaire for Children, respectively [34].

Diet acceptability The study dietitian conducted a standard interview with participants at 8 weeks to determine VLED acceptability. Participants were asked whether they liked the meal replacements, what they liked most and least about the diet, whether eating with friends or family was affected, and whether they would recommend a VLED for young people with type 2 diabetes.

Adherence Due to the low-energy content, adherence to a VLED will lead to weight loss. Adherence was defined as having $\geq 5 \%$ body weight loss during the 8 week VLED [10, 35].

\section{Statistical analysis}

Data were analysed using IBM SPSS Statistics Software for Windows, version 22 (IBM, Armonk, NY, USA). The Shapiro-Wilk test was used to assess normality of variables at baseline, and, if significant, data were treated as non-parametric. Changes in outcomes from baseline to 8 weeks were determined using paired sample $t$ tests and Wilcoxon's signed rank tests as appropriate. When assessing data by adherence, variables were 
treated as non-parametric due to small sample sizes and were reported as median (range). Missing data were excluded.

\section{Results}

\section{Participants}

Twenty youth were referred to the study: eight were enrolled, five were ineligible and seven declined participation (Fig. 1). The two youngest participants were siblings aged 7 and 9 years. Diabetes duration at enrolment ranged from $<1$ month to 3.25 years. All but one participant had a diagnosis duration of 6 months or less. Participants were born in Australia $(n=7)$ or New Zealand $(n=1)$, but six spoke a language other than English at home. All parents were born overseas, with ethnicities comprising: Middle Eastern $(n=2)$, South East Asian $(n=3)$, Pacific Islander $(n=6)$ and Fijian Indian $(n=4)$. Three participants lived in a single parent family, $36 \%$ of parents had a highest level of education of year 10 or below, and $21 \%$ had completed technical school or tertiary education. All participants reported a family history of type 2 diabetes: seven had a parent with diabetes (two with gestational diabetes, five with type 2 diabetes), and six had a second-degree relative with diabetes.

\section{Baseline characteristics}

All participants had a waist-to-height ratio $\geq 0.5$ (Table 1 ). The two male and four of the six female participants were in Tanner stage 3 or above at baseline. Three participants had dyslipidaemia, three had elevated BP, five had elevated liver

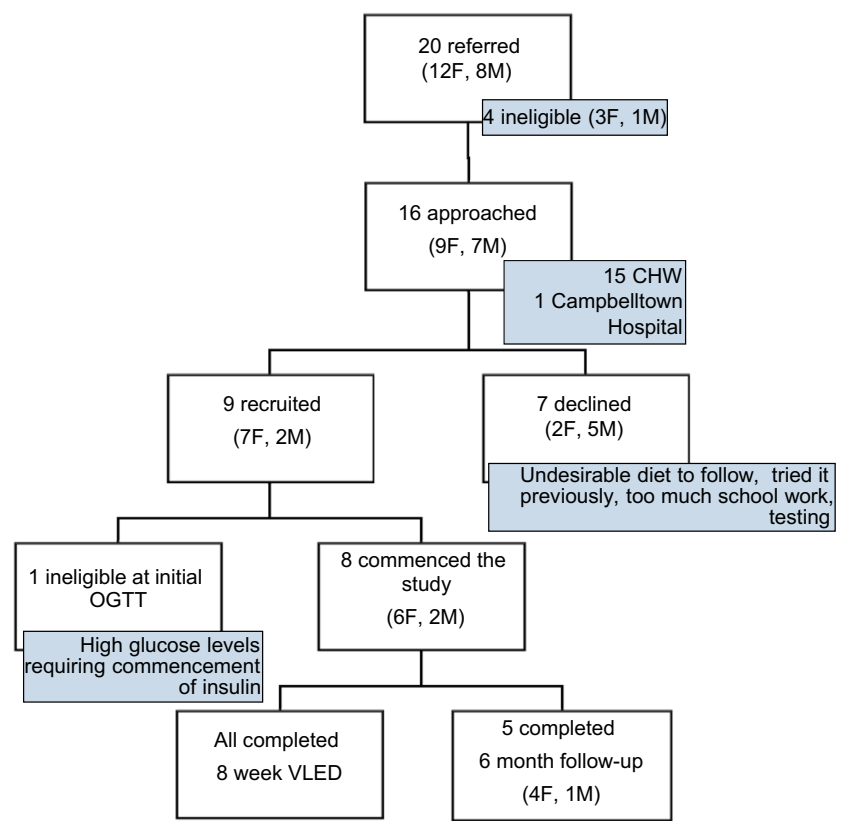

Fig. 1 SHAKE IT study participant flow. CHW, The Children's Hospital at Westmead; F, female; M, male enzymes and one had microalbuminuria. At baseline, four participants had elevated FPG $(\geq 7.0 \mathrm{mmol} / \mathrm{l})$, six had elevated $2 \mathrm{hG}$ ( $\geq 11.1 \mathrm{mmol} / \mathrm{l})$ and five had elevated $\mathrm{HbA}_{1 \mathrm{c}}(\geq 6.5 \%[\geq 48 \mathrm{mmol} /$ mol]). While all participants had a previous diagnosis of type 2 diabetes, two did not meet ADA criteria.

\section{8 weeks}

All participants completed the 8 week VLED (Table 1), achieving a mean (SD) weight loss of $4.1(4.0) \mathrm{kg}$, equivalent to $5.0 \%$ $(4.3 \%)$ body weight $(p=0.024)$. Five participants who had lost $\geq 5 \%$ body weight at 8 weeks were considered to be diet adherers (Fig. 2). Adherers had a median weight loss of $7.5 \%$ (Table 2), with two of five adherers no longer obese at 8 weeks. Predictably, non-adherers had less weight loss (median reduction $0.5 \%$ ), which was significantly less than that of adherers $(p=0.036)$.

At 8 weeks, $2 \mathrm{hG}$ and $\mathrm{HbA}_{1 \mathrm{c}}$ were significantly reduced compared with baseline (Table 1$)$. Adherers also had a significant reduction in fasting insulin $(p=0.043)$ and increase in insulin sensitivity ( $p=0.043$; Table 2$)$. At 8 weeks, one participant had elevated FPG, five had elevated $2 \mathrm{hG}$ and five had elevated $\mathrm{HbA}_{1 \mathrm{c}}$ consistent with type 2 diabetes. One of eight participants, an adherer who did not meet type 2 diabetes criteria at baseline, also did not meet the criteria at 8 weeks (Fig. 3).

Total cholesterol and triacylglycerol were also significantly reduced at 8 weeks compared with baseline (Table 1). At 8 weeks, six participants had obesity, six had dyslipidaemia, two had elevated BP, four had elevated liver enzymes and one had microalbuminuria.

\section{4 weeks}

All three non-adherers dropped out of the study before 34 weeks, while the five adherers completed the trial. At 34 weeks, four of five participants no longer met any criteria for type 2 diabetes (Fig. 3).

At 34 weeks, median (range) weight loss was 6.7 (3.4-13.2) $\mathrm{kg}$, or $12.3 \%(3.7-14.3 \%)$ body weight, with only two participants considered obese. Four achieved further weight loss (1.9-3.4 kg) during follow-up, whereas one gained weight $(3.6 \mathrm{~kg})$.

At 34 weeks, two had dyslipidaemia, one had elevated BP, two had elevated liver enzymes and one had microalbuminuria. The prevalence of dyslipidaemia, elevated blood pressure, elevated liver enzymes and microalbuminuria among adherers remained largely unchanged throughout the trial.

\section{Metformin and insulin therapy}

Seven participants were on metformin and three were on insulin therapy at baseline. All on metformin at baseline continued therapy during the trial. The three participants 
Table 1 Anthropometry, glycaemia, hepatic and pancreatic fat, lipids, liver enzymes, quality of life and eating behaviours of SHAKE IT participants at baseline and 8 weeks

\begin{tabular}{|c|c|c|}
\hline Variable & Baseline $(n=8)$ & 8 weeks $(n=8)$ \\
\hline Age, median (range) & $14.4(7.5-16.8)$ & - \\
\hline \multicolumn{3}{|l|}{ Anthropometry } \\
\hline Obese, $n(\%)$ & $8(100)$ & $6(75)$ \\
\hline Weight, kg & $86.2(10.2)$ & $82.2(9.9)^{*}$ \\
\hline BMI $z$ score & $2.31(0.33)$ & $2.14(0.37)^{*}$ \\
\hline Waist circumference, $\mathrm{cm}$ & $102.7(5.3)$ & $101.4(6.0)$ \\
\hline Waist-to-height ratio & $0.65(0.02)$ & $0.64(0.03)$ \\
\hline \multicolumn{3}{|l|}{ Blood pressure } \\
\hline Systolic BP $z$ score & $1.2(0.5)$ & $0.6(0.4)$ \\
\hline Diastolic BP $z$ score & $0.5(0.3)$ & $0.0(0.2)^{*}$ \\
\hline \multicolumn{3}{|l|}{ Glycaemic control and insulin resistance } \\
\hline Fasting glucose, $\mathrm{mmol} / \mathrm{l}$ & $7.6(1.6)$ & $6.0(0.6)$ \\
\hline Fasting insulin, pmol/1 & $198.4(13.0)$ & $143.8(24.6)$ \\
\hline $2 \mathrm{hG}, \mathrm{mmol} / \mathrm{l}$ & $15.6(1.6)$ & $11.3(1.0)^{* *}$ \\
\hline $\mathrm{HbA}_{1 \mathrm{c}}, \%$ & $8.1(0.7)$ & $6.6(0.5)^{* *}$ \\
\hline $\mathrm{HbA}_{1 \mathrm{c}}, \mathrm{mmol} / \mathrm{mol}$ & $65(5)$ & $49(3) * *$ \\
\hline WBISI & $4.0(0.3)$ & $7.0(1.6)$ \\
\hline \multicolumn{3}{|l|}{ Liver and pancreatic fat concentration } \\
\hline Liver fat, $\%$ & $14.7(2.2)$ & $5.8(1.7)^{* *}$ \\
\hline Pancreatic fat, $\%$ & $7.6(2.3)$ & $6.3(2.5)$ \\
\hline \multicolumn{3}{|l|}{ Lipids and liver enzymes } \\
\hline Total cholesterol, $\mathrm{mmol} / \mathrm{l}$ & $4.3(0.3)$ & $3.7(0.3) *$ \\
\hline Triacylglycerol, mmol/l; median (range) ${ }^{\mathrm{c}}$ & $1.35(1.0-6.8)$ & $1.25(0.7-4.0)^{*}$ \\
\hline HDL cholesterol, mmol/1 & $1.1(0.1)$ & $0.9(0.1)$ \\
\hline LDL cholesterol, mmol/1 & $2.4(0.3)^{\mathrm{b}}$ & $2.1(0.2)^{\mathrm{b}}$ \\
\hline ALT, U/1 & $37.5(4.5)$ & $30.5(3.5)$ \\
\hline AST, U/l; median (range) ${ }^{\mathrm{c}}$ & $36.0(26-98)$ & $32.5(24-48)$ \\
\hline GGT, U/1 & $27.3(3.3)$ & $22.1(2.4)$ \\
\hline \multicolumn{3}{|l|}{ Quality of life } \\
\hline Total score (range) ${ }^{\mathrm{c}}$ & $76.8(27.3-94.6)$ & $86.9(42.4-96.7) *$ \\
\hline Physical health score & $75.8(4.3)$ & $86.3(3.8)^{*}$ \\
\hline  & $76.7(15.0-96.7)$ & $85.8(28.3-95.0)^{*}$ \\
\hline \multicolumn{3}{|l|}{ Eating behaviours } \\
\hline External eating score & $1.88(0.15)^{\mathrm{a}}$ & $1.77(0.18)$ \\
\hline Emotional eating score & $1.45(0.21)^{\mathrm{a}}$ & $1.55(0.25)^{\mathrm{a}}$ \\
\hline Restrained eating score & $2.47(0.14)^{\mathrm{a}}$ & $2.54(0.14)$ \\
\hline
\end{tabular}

All values are mean (SE) unless otherwise indicated

${ }^{\text {a }}$ One missing item of data (i.e. $n=7$ )

${ }^{\mathrm{b}}$ Two missing items of data (i.e. $n=6$ )

${ }^{\mathrm{c}}$ Wilcoxon's signed rank test

Differences between baseline and 8 weeks were assessed using paired sample $t$ tests unless otherwise specified $* p<0.05$ versus baseline

$* * p<0.01$ versus baseline

AST, aspartate aminotransferase on insulin at baseline, all diet adherers, ceased insulin during phase I: one in week 6 and the other two by day 10 of the VLED. Insulin was not recommenced during the study for any participant.

\section{Liver and pancreatic fat}

At baseline, all participants met NAFLD criteria. Overall, participants had a $60.5 \%$ mean relative reduction in liver fat from 
Fig. 2 Individual participant weight loss of (a) adherers and (b) non-adherers at 8 (black bars) and 34 weeks (white bars)

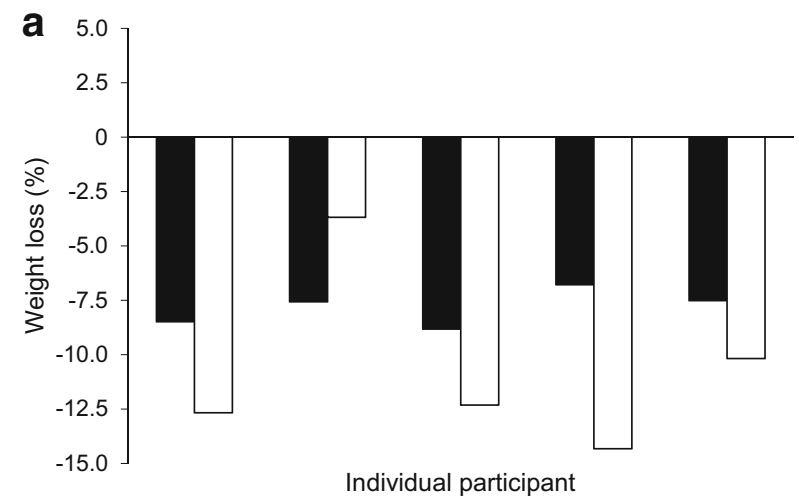

baseline to 8 weeks (Table 1), with only three of eight participants meeting NAFLD criteria at 8 weeks. At 34 weeks, no participant had a liver fat concentration consistent with NAFLD. In adherers, liver fat was reduced at 8 and 34 weeks compared with baseline ( $p=0.043$ for both time points; Table 2), achieving relative reductions equivalent to a median of $74 \%$ and $78 \%$, respectively. At 8 weeks, non-adherers had a median reduction in liver fat of $49 \%(p=0.109)$.

A significant pancreatic fat signal was detected in six of eight participants at baseline (three adherers and three nonadherers), but the lipid signal in two individuals was negligible. At 8 weeks, the six individuals with baseline pancreatic fat had achieved a median relative reduction of $23 \%$ (Table 1), but this was not statistically significant. The three adherers had a $4 \%$ and $19 \%$ reduction at 8 and 34 weeks, respectively. The three non-adherers had a $32 \%$ reduction at 8 weeks.

\section{Quality of life and eating behaviours}

Total HRQOL, physical health and psychosocial health summary scores significantly improved from baseline to 8 weeks (Table 1). There were no significant differences in scores between adherers and non-adherers at baseline or at 8 weeks. However, there was a trend towards a higher psychosocial health summary score and total HRQOL score among adherers (Table 2). Adherers had improvements in physical health and total HRQOL scores from baseline to 8 weeks ( $p=0.043$ for both). This was maintained at 34 weeks for physical health score only $(p=0.042)$. There were no significant changes among non-adherers.

There were no significant temporal changes in external, emotional or restrained eating. Although not significant, median scores were lower for diet adherers compared with nonadherers on all subscales at baseline and at 8 weeks.

\section{Acceptability of the diet}

Seven of eight participants completed the acceptability interview at 8 weeks (one non-adherer did not). Three participants (all adherers) reported liking the taste of the VLED products. Four participants reported weight loss to be the best thing about the diet, with other positive factors including less hunger, cessation of insulin therapy and the rigid diet structure. When asked what they liked least about the diet, participants noted: the taste $(n=4)$, difficulty adjusting to the diet $(n=2)$ and the regular eating prescribed $(n=1)$. Four found it difficult to go out with friends, while three reported supportive friends. Family life was more difficult in two cases due to increased food preparation required and other family members eating foods that the participant could not. Five participants (including one non-adherer) would recommend this diet for young people with type 2 diabetes due to the associated weight loss, cessation of insulin therapy and better glycaemic control. Two would not recommend the diet due to the taste and rigidity of the diet.

\section{Discussion}

This is the first prospective study in youth to demonstrate that a VLED is an acceptable and feasible treatment option for some youth with type 2 diabetes and that adherence can lead to reversal of type 2 diabetes as seen in adult studies [10-13]. An intense diet intervention may be more effective than standard practice, based on prescription of a less intensive lifestyle intervention with pharmacotherapy.

The TODAY study, a large US multicentre randomised clinical trial comparing treatment options for 69910 - to 17-year-olds with type 2 diabetes, found that therapy based on current clinical practice guidelines [6] (metformin plus lifestyle intervention) was ineffective for maintaining glycaemic control in nearly $50 \%$ of participants after 1 year of treatment, despite 6 months of weekly face-to-face sessions [36]; hence, the TODAY study, together with the evidence for early diabetes-related complications [3, 4], highlights the need for aggressive therapies that commence immediately or early after diagnosis. Bariatric surgery may be a feasible alternative, with one study demonstrating reversal of type 2 diabetes in ten of 11 adolescents [37]. However, our study demonstrates that, if adhered to, a VLED may be as effective and possibly safer for youth, in whom the long-term effects of bariatric surgery, 
Table 2 Adherers' and non-adherers' anthropometry, glycaemic control, hepatic and pancreatic fat, lipids and liver enzymes during the SHAKE IT study

\begin{tabular}{|c|c|c|c|c|c|}
\hline \multirow[t]{2}{*}{ Variable } & \multicolumn{2}{|l|}{ Baseline } & \multicolumn{2}{|l|}{8 weeks } & \multirow{2}{*}{$\begin{array}{l}34 \text { weeks } \\
(\text { adherers }[n=5])\end{array}$} \\
\hline & Adherers $(n=5)$ & Non-adherers $(n=3)$ & Adherers $(n=5)$ & $\begin{array}{l}\text { Non-adherers } \\
(n=3)\end{array}$ & \\
\hline Age & $14.7(7.5$ to 16.8$)$ & $14.2(13.7$ to 14.7$)$ & - & - & - \\
\hline \multicolumn{6}{|l|}{ Anthropometry } \\
\hline Obese, $n(\%)$ & $5(100)$ & $3(100)$ & $3(60)^{*}$ & $3(100)$ & $2(40)$ \\
\hline Weight, kg & $81.3(39.8$ to 133.6$)$ & $97.0(88.8$ to 102.9$)$ & $74.4(37.1 \text { to } 123.6)^{*}$ & 96.5 (91.3 to 99.9$)$ & $71.0(34.1 \text { to } 120.4)^{*}$ \\
\hline BMI $z$ score & $2.17(2.1$ to 3.0$)$ & 2.25 (1.98 to 2.40$)$ & $1.83(1.81$ to 2.92$)$ & $2.11(2.02$ to 2.20$)$ & $1.59(1.24 \text { to } 2.87)^{*}$ \\
\hline Waist circumference, $\mathrm{cm}$ & $103.0(78.8$ to 130.9$)$ & $105.6(95.8$ to 108.5$)$ & $98.1(75.9$ to 133.2$)$ & $104.8(98.1$ to 111.4$)$ & $90.7(69.8 \text { to } 129.2)^{*}, * *$ \\
\hline Waist-to-height ratio & $0.66(0.60$ to 0.78$)$ & $0.63(0.55$ to 0.64$)$ & $0.64(0.60$ to 0.80$)$ & $0.62(0.56$ to 0.66$)$ & $0.58(0.52 \text { to } 0.77)^{*} * *$ \\
\hline \multicolumn{6}{|l|}{$\mathrm{BP}$} \\
\hline Systolic BP $z$ score & $0.7(-0.8$ to 2.1$)$ & $2.1(0.6$ to 3.3$)$ & $-0.1(-0.7$ to 2.2$)$ & $1.1(0.6$ to 1.7$)$ & $0.0(-0.9$ to 3.3$)$ \\
\hline Diastolic BP $z$ score & $0.3(-0.1$ to 1.3$)$ & $0.2(-0.6$ to 2.1$)$ & $-0.1(-0.5$ to 0.9$)$ & $-0.1(-0.8$ to 0.7$)$ & $-0.2(-0.7 \text { to } 0.2)^{*}$ \\
\hline \multicolumn{6}{|c|}{ Glycaemic control and insulin resistance } \\
\hline Fasting glucose, $\mathrm{mmol} / \mathrm{l}$ & $4.9(3.2$ to 8.5$)$ & $8.5(8.4$ to 17.1$)$ & $5.1(4.2$ to 6.6$)$ & $6.8(6.5$ to 9.1$)$ & 4.6 (4.2 to 11.2$)$ \\
\hline Fasting insulin, $\mathrm{pmol} / \mathrm{l}$ & 218 (199 to 244$)$ & $166(132 \text { to } 190)^{\mathrm{a}}$ & $71(46 \text { to } 210)^{*}$ & $196(164$ to 213$)$ & 135 (49 to 274$)$ \\
\hline $2 \mathrm{hG}, \mathrm{mmol} / \mathrm{l}$ & $14.1(10.3$ to 16.9$)$ & 16.7 (16.5 to 25.0$)$ & $9.7(7.2$ to 12.0$)$ & $13.7(11.4$ to 16.0$)$ & $10.4(7.3$ to 19.8$)$ \\
\hline $\mathrm{HbA}_{1 \mathrm{c}}, \%$ & $6.4(5.0$ to 9.4$)$ & $8.8(8.2$ to 11.3$)$ & $6.1(4.8 \text { to } 7.2)^{*}$ & $7.3(6.9$ to 8.9$)$ & $5.7(4.9 \text { to } 8.5)^{*}$ \\
\hline $\mathrm{HbA}_{1 \mathrm{c}}, \mathrm{mmol} / \mathrm{mol}$ & $46(31$ to 79$)$ & $73(66$ to 100$)$ & $43(29 \text { to } 55)^{*}$ & $56(52$ to 74$)$ & $39(30 \text { to } 69)^{*}$ \\
\hline WBISI & $4.1(3.1$ to 5.0$)$ & $4.2(3.1$ to 4.3$)$ & $9.3(3.7 \text { to } 14.9)^{*}$ & $3.6(3.6$ to 5.0$)$ & $8.1(2.3$ to 13.7$)$ \\
\hline \multicolumn{6}{|c|}{ Liver and pancreatic fat concentration } \\
\hline Liver fat, $\%$ & 15.7 (6.9 to 27.3$)$ & $11.0(11.0$ to 16.5$)$ & $1.9(1.8 \text { to } 13.7)^{*}$ & $5.6(5.1$ to 12.9$)$ & $2.7(2.0 \text { to } 5.4)^{*}$ \\
\hline Pancreatic fat, $\%$ & 3.3 (negligible to 13.88 ) & $8.8(8.8$ to 18.4$)$ & 3.2 (negligible to 14.3 ) & $6.0(2.5$ to 19.3$)$ & 1.5 (negligible to 11.2 ) \\
\hline \multicolumn{6}{|l|}{ Lipids and liver enzymes } \\
\hline Total cholesterol, mmol/1 & $3.8(3.6$ to 5.2$)$ & $5.1(3.3$ to 5.4$)$ & $3.3(2.8 \text { to } 4.7)^{*}$ & $3.8(3.5$ to 5.0$)$ & $3.8(3.2$ to 4.6$)$ \\
\hline Triacylglycerol, mmol/1 & $1.3(1.1$ to 1.5$)$ & $2.8(1.0$ to 6.8$)$ & $0.8(0.7 \text { to } 1.4)^{*}$ & $2.2(1.2$ to 4.0$)$ & $0.9(0.4$ to 1.4$)$ \\
\hline HDL cholesterol, $\mathrm{mmol} / \mathrm{l}$ & $1.1(1.1$ to 1.4$)$ & $0.9(0.9 \text { to } 0.9)^{\mathrm{a}}$ & $1.0(0.6 \text { to } 1.1)^{*}$ & $1.1(0.7$ to 1.2$)$ & $1.2(1.0$ to 1.6$)$ \\
\hline LDL cholesterol, mmol/1 & $2.0(1.7$ to 3.4$)$ & $1.9^{\mathrm{b}}$ & $1.7(1.5 \text { to } 2.4)^{\mathrm{c}}$ & $1.9(1.8 \text { to } 2.0)^{\mathrm{c}}$ & $2.0(1.6$ to 3.0$)$ \\
\hline ALT, U/1 & $28(23$ to 54$)$ & 45 (32 to 56$)$ & $28(14$ to 38$)$ & $40(22$ to 44$)$ & $21(17 \text { to } 34)^{*}$ \\
\hline AST, U/1 & 34 (26 to 38$)$ & 40 (35 to 98$)$ & 33 (26 to 35$)$ & $32(24$ to 48$)$ & $28(14$ to 34$)$ \\
\hline GGT, U/1 & $22(11$ to 33$)$ & $34(34 \text { to } 39)^{\mathrm{a}}$ & $17(13$ to 30$)$ & $26(25$ to 30$)$ & $13(10$ to 34$)$ \\
\hline
\end{tabular}

All values are median (range) unless otherwise indicated

Differences between adherers and non-adherers were assessed using Mann-Whitney $U$ tests. Changes from baseline to 8 weeks (and 34 weeks for adherers) were assessed using Wilcoxon's signed rank tests for adherers and non-adherers separately

*Significant difference in adherers at 8 and/or 34 weeks vs baseline $(p<0.05)$; there were no significant changes from baseline to 8 weeks in non-adherers

**Significant difference in adherers at 34 weeks vs 8 weeks $(p<0.05)$

${ }^{a}$ Significant difference between adherers and non-adherers at baseline $(p<0.05)$; there were no significant differences between adherers and nonadherers at 8 weeks

${ }^{\mathrm{b}}$ Two missing items of data

${ }^{\mathrm{c}}$ One missing item of data

AST, aspartate aminotransferase

both physical and mental, are largely unknown [38]. Previous adult studies have also highlighted the potential of a VLED to facilitate the reversal of type 2 diabetes, prescribing energy intakes of 1680-2940 kJ/day over a duration lasting between 7 days and 16 weeks [10-13].

\section{Presence of type 2 diabetes and intra-organ fat reductions}

Previous small studies in adults with type 2 diabetes have demonstrated remarkable metabolic effects of a short-term VLED [10-13]. Lim et al [10] demonstrated normalisation of FPG and insulin sensitivity after 7 days. The authors attributed these findings to significant reductions in liver fat $(30 \%$ in 7 days). By contrast, in our study, only one participant did not meet any ADA criteria for type 2 diabetes after 8 weeks, despite similarly dramatic reductions in liver fat among adherers. However, the adult study [10] defined type 2 diabetes according to FPG levels only, which is less diagnostically sensitive than $2 \mathrm{hG}$ [39]. Our observation of no change in ALT with the 8 week diet intervention, but subsequent decline in the longer term, is consistent with some lifestyle intervention data in adults which demonstrate its questionable utility as a short-term marker of hepatic steatosis change [40].

Faster deterioration of beta cells is reported in youth with insulin resistance and type 2 diabetes compared with adults; hence, greater and sustained weight loss may be required to reverse type 2 diabetes in youth $[41,42]$. In the present study, 8 week weight loss might not have been sufficient and liver fat 
a

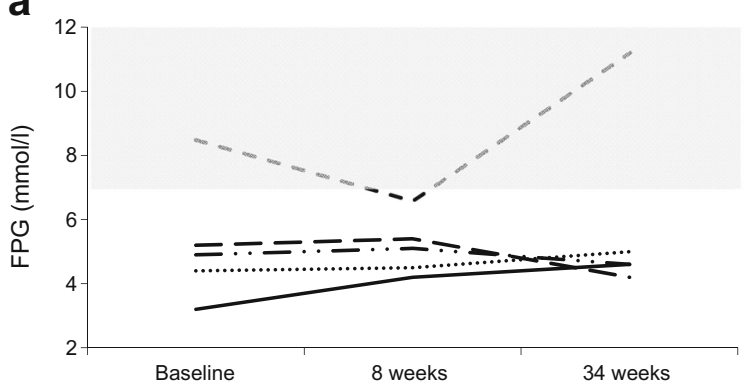

b

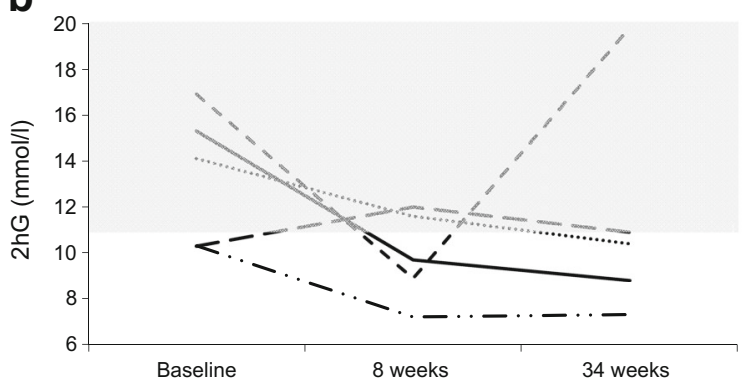

C

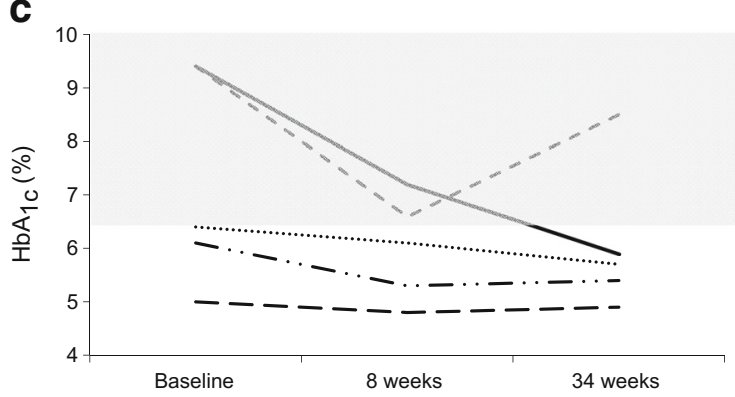

Fig. 3 Changes in type 2 diabetes criteria over the study period (baseline, 8 and 34 weeks) for adherers. Each line represents a different participant. (a) FPG; (b) $2 \mathrm{hG}$; (c) $\mathrm{HbA}_{1 \mathrm{c}}$. The grey area represents the presence of type 2 diabetes, i.e. meeting criteria for FPG ( $\geq 7.0 \mathrm{mmol} / \mathrm{l}), 2 \mathrm{hG}(\geq 11.1 \mathrm{mmol} /$ 1) and/or $\mathrm{HbA}_{1 \mathrm{c}}(\geq 6.5 \%[\geq 48 \mathrm{mmol} / \mathrm{mol}])$. To convert values for $\mathrm{HbA}_{1 \mathrm{c}}$ in per cent into $\mathrm{mmol} / \mathrm{mol}$, subtract 2.15 and multiply by 10.929

remained too high (5.8\% [SE 1.7\%]) to achieve reversal. At 34 weeks, median weight loss was $12.3 \%$ and median liver fat was $2.7 \%$, at which point reversal was achieved by four of the five adherers. This suggests that $\geq 10 \%$ weight loss and a liver fat concentration below the threshold associated with NAFLD $(\leq 5.5 \%)[31,32]$ may be required to reverse type 2 diabetes in youth.

One adherer did not experience type 2 diabetes reversal at 34 weeks, despite $9.9 \%$ weight loss and $66 \%$ liver fat reduction. However, this participant's liver fat was still $5.35 \%$ at 34 weeks, suggesting further weight loss and hepatic lipid reduction may be necessary to induce type 2 diabetes reversal. Furthermore, this participant had a $2 \mathrm{~kg}$ weight gain in the month prior to the 34 week visit, possibly due to short-term carbohydrate overfeeding, which has been demonstrated to induce hepatic lipid accumulation [43]. This participant also had the greatest requirement for insulin and the longest duration of diabetes at enrolment (3.25 years). All other participants commenced the trial within 6 months of diagnosis, suggesting the importance of early intervention.

A reduction in pancreatic fat is also thought to be important for type 2 diabetes reversal: a study in adults demonstrated that a reduction in pancreatic fat from $6.6 \%$ to $5.4 \%$, achieved by $15 \%$ body weight loss following gastric bypass, was associated with type 2 diabetes reversal [44]. Using non-invasive spectroscopy, which has been shown to have good reliability and validity in adults [45], we observed significant pancreatic fat in the majority, but negligible pancreatic fat in two individuals. These pilot data may suggest that type 2 diabetes can manifest in youth without the presence of pancreatic fat, but more data concerning the association between pancreatic fat and metabolic health, and its response to therapeutic interventions, are required.

\section{Weight loss and insulin therapy maintenance}

Four of five participants had additional modest weight loss (median $3.0 \mathrm{~kg}$ ) during follow-up. In a study in adults, participants gained weight (mean $13 \mathrm{~kg}$ ) during the 14 month period following the VLED intervention [12]. As our study participants did not experience type 2 diabetes reversal until 34 weeks, maintenance of weight loss is clearly important to achieve reversal of type 2 diabetes and avoid re-infiltration of fat into the liver. It is likely that long-term weight loss maintenance therapy is required following a short-term VLED to ensure persistent remission of type 2 diabetes.

All three participants on insulin therapy at baseline ceased insulin therapy during the 8 week VLED and remained off insulin throughout the trial. This is clearly a significant benefit and may influence the decision to participate in a VLED intervention.

\section{Quality of life and eating behaviours}

Baseline total HRQOL in our study participants was comparable to that of previous studies using the PedsQL in youth with type 2 diabetes $[33,46]$. Despite the strict and difficult nature of a VLED, quality of life improved from baseline to 8 weeks. This may be related to the cessation of insulin therapy, but it also suggests that a VLED does not detrimentally impact quality of life. This is further exemplified by the generally positive comments received during acceptability interviews.

There was a non-significant trend for non-adherers to have poorer HRQOL and more deranged eating behaviours compared with adherers. These psychological impairments may affect motivation and ability to succeed in an intense dietary programme. Psychologist involvement may be necessary to address underlying psychopathology prior to VLED commencement. Of note, eating styles did not change throughout 
the study, suggesting that an intense diet approach does not induce abnormal eating styles in youth.

\section{Strengths and limitations}

This is the first time in the literature that the potential of a VLED to reverse type 2 diabetes in youth on metformin therapy has been demonstrated. To the best of our knowledge, this is also the first study to report changes in HRQOL and eating behaviours in youth with type 2 diabetes participating in an intervention. Other strengths of our study are the inclusion of youth on insulin therapy, the use of ${ }^{1} \mathrm{H}$-MRS to quantify intraorgan fat, and the ability to determine the presence or absence of type 2 diabetes according to all ADA criteria using an OGTT.

There are study limitations. Only eight youth were recruited to the trial; this is partly due to type 2 diabetes being relatively uncommon in those aged $<18$ years. Because of the small numbers, many findings that are clinically significant were not statistically significant, thus limiting the interpretation of our results. Although only eight participants were recruited, 16 were approached of whom seven declined the trial, suggesting that, despite the potential to reverse their condition, this difficult dietary option is not always acceptable. Furthermore, with no controls in this proof-of-concept trial, a bigger study, with an appropriate control sample, is needed to confirm our findings. Although the ${ }^{1} \mathrm{H}-\mathrm{MRS}$ approach used for pancreatic fat quantification has been shown to be reliable [45], results can be confounded by respiratory movement. Therefore, it is inappropriate to conclude on the efficacy of dietary intervention for pancreatic fat modification from this small pilot study. Finally, little is known about whether reversal of type 2 diabetes is sustainable. Future studies should consider a longer follow-up period with continued support.

In conclusion, a VLED appears to be a feasible and acceptable treatment option for some youth with type 2 diabetes treated with metformin. Benefits include no further requirement for insulin therapy, enhanced glycaemic control and improved quality of life. There are also likely to be long-term benefits, which may include fewer diabetes complications and an extended lifespan for the individual, as well as societal benefits including reduced healthcare costs and increased workforce productivity. Furthermore, reversal of type 2 diabetes is possible for youth who accept and adhere to a short-term VLED followed by ongoing dietary support, highlighting the capacity of its potential to be offered as first-line treatment.

Acknowledgements We would like to acknowledge T. Walker (Medical Imaging, The Children's Hospital at Westmead, Sydney, NSW, Australia) and K. Heels, L. Lawrie and K. Winning (Institute of Endocrinology and Diabetes, The Children's Hospital at Westmead, Sydney, NSW, Australia) for their contribution to the clinical care of participants and data collection for this trial.
Data availability The datasets generated and analysed during the current study are available from the corresponding author on reasonable request.

Funding This work was supported by an Australian postgraduate doctoral award to MLG, a Diabetes Australia Research Trust grant to SPG, LAB and CTC (Y14G-GARS), and by Nestlé Australia through provision of Optifast meal replacements for the trial.

Duality of interest The authors declare that there is no duality of interest associated with this manuscript.

Contribution statement MLG contributed to the study design, collected and analysed the data and drafted the manuscript. NAJ contributed to the spectroscopy methodology, analysed the spectroscopy and reviewed/ edited the manuscript. LAB, CTC and SPG obtained study funding, contributed to the study design and reviewed/edited the manuscript. All authors approved the final version of the manuscript. MLG is the guarantor of this work.

\section{References}

1. Fazeli Farsani S, van der Aa MP, van der Vorst MM, Knibbe CA, de Boer A (2013) Global trends in the incidence and prevalence of type 2 diabetes in children and adolescents: a systematic review and evaluation of methodological approaches. Diabetologia 56: 1471-1488

2. Dabelea D, Mayer-Davis EJ, Saydah S, for the Search for Diabetes in Youth Study Group et al (2014) Prevalence of type 1 and type 2 diabetes among children and adolescents from 2001 to 2009. JAMA 311:1778-1786

3. Constantino MI, Molyneaux L, Limacher-Gisler F et al (2013) Long-term complications and mortality in young-onset diabetes: type 2 diabetes is more hazardous and lethal than type 1 diabetes. Diabetes Care 36:3863-3869

4. The TODAY Study Group (2013) Rapid rise in hypertension and nephropathy in youth with type 2 diabetes: the TODAY clinical trial. Diabetes Care 36:1735-1741

5. Zeitler P, Fu J, Tandon $\mathrm{N}$ et al (2014) ISPAD clinical practice consensus guidelines 2014. Type 2 diabetes in the child and adolescent. Pediatr Diabetes 15(Suppl 20):26-46

6. Copeland KC, Silverstein J, Moore KR, for the American Academy of Pediatrics et al (2013) Management of newly diagnosed type 2 diabetes mellitus (T2DM) in children and adolescents. Pediatrics 131:364-382

7. Zeitler P, Hirst K, Pyle L et al (2012) A clinical trial to maintain glycemic control in youth with type 2 diabetes. N Engl J Med 366: 2247-2256

8. George MM, Copeland KC (2013) Current treatment options for type 2 diabetes mellitus in youth: today's realities and lessons from the TODAY study. Curr Diab Rep 13:72-80

9. Taylor R (2013) Type 2 diabetes: etiology and reversibility. Diabetes Care 36:1047-1055

10. Lim EL, Hollingsworth KG, Aribisala BS, Chen MJ, Mathers JC, Taylor R (2011) Reversal of type 2 diabetes: normalisation of beta cell function in association with decreased pancreas and liver triacylglycerol. Diabetologia 54:2506-2514

11. Malandrucco I, Pasqualetti P, Giordani I et al (2012) Very-lowcalorie diet: a quick therapeutic tool to improve beta cell function 
in morbidly obese patients with type 2 diabetes. Am J Clin Nutr 95: 609-613

12. Snel M, Jonker JT, Hammer S et al (2012) Long-term beneficial effect of a 16 week very low calorie diet on pericardial fat in obese type 2 diabetes mellitus patients. Obesity 20:1572-1576

13. Steven S, Hollingsworth KG, Al-Mrabeh A et al (2016) Very lowcalorie diet and 6 months of weight stability in type 2 diabetes: pathophysiological changes in responders and nonresponders. Diabetes Care 39:808-815

14. American Diabetes Association (2014) Diagnosis and classification of diabetes mellitus. Diabetes Care 37(Suppl 1):S81-90

15. Cole TJ, Lobstein T (2012) Extended international (IOTF) body mass index cut-offs for thinness, overweight and obesity. Pediatr Obes 7:284-294

16. Tanner JM, Whitehouse RH (1976) Clinical longitudinal standards for height, weight, height velocity, weight velocity, and stages of puberty. Arch Dis Child 51:170-179

17. Kuczmarski RJ, Ogden CL, Guo SS et al (2002) 2000 CDC growth charts for the United States: methods and development. Vital Health Stat 11(2002):1-190

18. Zimmet P, Alberti KG, Kaufman F et al (2007) The metabolic syndrome in children and adolescents - an IDF consensus report. Pediatr Diabetes 8:299-306

19. Prati D, Taioli E, Zanella A et al (2002) Updated definitions of healthy ranges for serum alanine aminotransferase levels. Ann Intern Med 137:1-10

20. Rochling FA (2001) Evaluation of abnormal liver tests. Clin Cornerstone 3:1-12

21. Matsuda M, DeFronzo RA (1999) Insulin sensitivity indices obtained from oral glucose tolerance testing: comparison with the euglycemic insulin clamp. Diabetes Care 22:1462-1470

22. Donaghue KC, Chiarelli F, Trotta D, Allgrove J, Dahl-Jorgensen K (2009) Microvascular and macrovascular complications associated with diabetes in children and adolescents. Pediatr Diabetes 10(Suppl 12):195-203

23. National High Blood Pressure Education Program Working Group on High Blood Pressure in Children and Adolescents (2004) The fourth report on the diagnosis, evaluation, and treatment of high blood pressure in children and adolescents. Pediatrics 114:555-576

24. Johnson NA, Walton DW, Sachinwalla T et al (2008) Noninvasive assessment of hepatic lipid composition: advancing understanding and management of fatty liver disorders. Hepatology 47:1513-1523

25. Naressi A, Couturier C, Devos JM et al (2001) Java-based graphical user interface for the MRUI quantitation package. MAGMA 12: $141-52$

26. Stefan D, Cesare FD, Andrasescu A et al (2009) Quantitation of magnetic resonance spectroscopy signals: the jMRUI software package. Meas Sci Technol 20:104035

27. Keating SE, Hackett DA, Parker HM et al (2015) Effect of aerobic exercise training dose on liver fat and visceral adiposity. J Hepatol 63:174-182

28. Pijnappel WWF, van den Boogaart A, de Beer R, van Ormondt D (1992) SVD-based quantification of magnetic resonance signals. J Magn Reson 97:122-134

29. van den Boogaart A, van Ormondt D, Pijnappel WWF, de Beer R, Ala-Korpela M (1994) In: McWhirter JG (ed) Mathematics in signal processing III. Clarendon Press, Oxford, pp 175-195
30. Johnson NA, Sachinwalla T, Walton DW et al (2009) Aerobic exercise training reduces hepatic and visceral lipids in obese individuals without weight loss. Hepatology 50:1105-1112

31. Kim G, Giannini C, Pierpont B et al (2013) Longitudinal effects of MRI-measured hepatic steatosis on biomarkers of glucose homeostasis and hepatic apoptosis in obese youth. Diabetes Care 36:130 136

32. Fabbrini E, Sullivan S, Klein S (2010) Obesity and nonalcoholic fatty liver disease: biochemical, metabolic, and clinical implications. Hepatology 51:679-689

33. Varni JW, Burwinkle TM, Jacobs JR, Gottschalk M, Kaufman F, Jones KL (2003) The PedsQL in type 1 and type 2 diabetes: reliability and validity of the Pediatric Quality of Life Inventory Generic Core Scales and Type 1 Diabetes Module. Diabetes Care 26:631-637

34. van Strien T, Oosterveld P (2008) The children's DEBQ for assessment of restrained, emotional, and external eating in 7- to 12-yearold children. Int J Eat Disord 41:72-81

35. Figueroa-Colon R, von Almen TK, Franklin FA, Schuftan C, Suskind RM (1993) Comparison of two hypocaloric diets in obese children. Am J Dis Child 147:160-166

36. The TODAY Study Group (2007) Treatment options for type 2 diabetes in adolescents and youth: a study of the comparative efficacy of metformin alone or in combination with rosiglitazone or lifestyle intervention in adolescents with type 2 diabetes. Pediatr Diabetes 8:74-87

37. Inge TH, Miyano G, Bean J et al (2009) Reversal of type 2 diabetes mellitus and improvements in cardiovascular risk factors after surgical weight loss in adolescents. Pediatrics 123:214-222

38. Hofmann B (2013) Bariatric surgery for obese children and adolescents: a review of the moral challenges. BMC Med Ethics 14:18

39. NCD Risk Factor Collaboration (2015) Effects of diabetes definition on global surveillance of diabetes prevalence and diagnosis: a pooled analysis of 96 population-based studies with 331,288 participants. Lancet Diabetes Endocrinol 3:624-637

40. Thoma C, Day CP, Trenell MI (2012) Lifestyle interventions for the treatment of non-alcoholic fatty liver disease in adults: a systematic review. J Hepatol 56:255-266

41. Gungor N, Arslanian S (2004) Progressive beta cell failure in type 2 diabetes mellitus of youth. J Pediatr 144:656-659

42. Giannini C, Weiss R, Cali A et al (2012) Evidence for early defects in insulin sensitivity and secretion before the onset of glucose dysregulation in obese youths: a longitudinal study. Diabetes 61:606-614

43. Sevastianova K, Santos A, Kotronen A et al (2012) Effect of shortterm carbohydrate overfeeding and long-term weight loss on liver fat in overweight humans. Am J Clin Nutr 96:727-734

44. Steven S, Hollingsworth KG, Small PK et al (2016) Weight loss decreases excess pancreatic triacylglycerol specifically in type 2 diabetes. Diabetes Care 39:158-165

45. Lingvay I, Esser V, Legendre JL et al (2009) Noninvasive quantification of pancreatic fat in humans. J Clin Endocrinol Metab 94: 4070-4076

46. Naughton MJ, Ruggiero AM, Lawrence JM, for the Search for Diabetes in Youth Study Group et al (2008) Health-related quality of life of children and adolescents with type 1 or type 2 diabetes mellitus: SEARCH for Diabetes in Youth Study. Arch Pediatr Adolesc Med 162:649-657 